\title{
ANALISIS SAMBUNGAN SEKRUP PADA KONSTRUKSI RANGKA ATAP BAJA RINGAN MENURUT SNI 7971:2013
}

\author{
Widya Apriani \\ Program Studi Teknik Sipil Universitas Lancang Kuning \\ Jalan Yos Sudarso Km. 8 Rumbai Pekanbaru \\ E-mail : Widyaapriani@unilak.ac.id \\ Fadrizal Lubis \\ Program Studi Teknik Sipil Universitas Lancang Kuning \\ Jalan Yos Sudarso Km. 8 Rumbai Pekanbaru \\ E-mail : fadrizal@unilak.ac.id \\ Muthia Anggraini \\ Program Studi Teknik Sipil Universitas Lancang Kuning \\ Jalan Yos Sudarso Km. 8 Rumbai Pekanbaru \\ E-mail : muthia@unilak.ac.id
}

\begin{abstract}
Abstrak
Kegagalan struktur rangka atap bangunan dengan material baja ringan atau baja canai dingin dapat terjadi oleh beberapa sebab, misalnya faktor perencanaan dan pelaksanaan. Pada tahun 2016 terjadi kegagalan struktur rangka atap pada suatu gedung di Pekanbaru yang mengakibatkan hampir keseluruhan rangka atap bangunan rubuh. Kegagalan yang terjadi pada sambungan dan tekuk di beberapa batang yang terjadi pada beberapa joint atau sambungan antara ringbalk beton dan rangka batang. Penelitian dilakukan dengan melakukan pemodelan rangka atap baja canai dingin menggunakan SAP 2000 untuk mengetahui gaya dalam struktur. selanjutnya dilakukan desain sambungan menurut SNI 7971:2013 tentang baja canai. Sambungan yang akan dianalisis merupakan sambungan rangka baja ringan dengan menggunakan self-drilling screw yang didesain menurut ketentuan SNI 7971:2013. Hasil penelitian menunjukkan terjadi kegagalan sambungan yang dipengaruhi oleh mode bearing, karena kapasitas geser desain yang diperoleh lebih besar dari kapasitas tariknya, sehingga jumlah sekrup yang digunakan lebih sedikit. Kapasitas sambungan pada kasus ini ditentukan oleh kapasitas geser sekrup. Desain kapasitas geser sedikit di atas gaya dalam maksimum yang bekerja. Sedangkan, kapasitas tarik profil jauh kapasitas geser yang bekerja. Sambungan cukup kuat menahan gaya-gaya dalam rangka baja ringan yang menahan kombinasi beban gravitasi dan beban angin, beban hujan, sehingga sambungan bukanlah menjadi penyebab terjadinya keruntuhan struktur rangka atap.
\end{abstract}

Kata Kunci : $\quad$ Sambungan Sekrup, Keruntuhan Rangka Atap, SNI 7971:2013 


\begin{abstract}
Failure of building roof frame structure with cold formed steel can occur by several reasons, such as planning and implementation factors. In 2016 there was a failure of roof frame structure at one of building in Pekanbaru which resulted in almost the entire roof frame collapsed. Failure that occurs in connection and buckling in multiple stems that occur in some joints between concrete and concrete ringbalk. The study was conducted by modeling cold rolled steel roof frames using SAP 2000 to find out the forces in the structure. furthermore, the design of the connection according to SNI 7971:2013 concerning the cold formed steel. The joints to be analyzed are joints using self-drilling screw designed according to SNI 7971:2013. The results show that the connection failure is affected by the bearing mode, therefore the shear capacity of the design obtained is greater than its tensile capacity. therefore the number of screws used is less. The connection capacity in this case is determined by the screw shear capacity. Design the shear capacity slightly above the maximum working force. Whereas, the capacity of tensile profile of the working shear capacity. Theconnection was enough to resist forces in the cold formed steel that withstand the combination of gravity load and wind load, rain load, so the connection is not the cause of the collapse of the roof truss structure.
\end{abstract}

Keywords : Screw Connection, Roof Frame Collapse, SNI 7971:2013

\section{A. PENDAHULUAN}

Rangka atap baja ringan di Indonesia kerap kali mengalami keruntuhan. Keruntuhan tersebut dapat disebabkan oleh kegagalan elemen kesalahan pengerjaan atau kegagalan sambungan sehingga diperlukan analisis. Analisis sambungan memiliki peranan penting dalam stabilitas dan keamanan struktur karena kegagalan struktur banyak ditentukan oleh desain sambungan (Nurjaman S, 2010). Pada penelitian ini studi kasus adalah keruntuhan rangka atap gedung SKPD Pekanbaru. Keseluruhan struktur mengalami kegagalan. Penelitian dilakukan dengan melakukan pemodelan rangka atap baja canai dingin menggunakan SAP 2000 untuk mengetahui gaya dalam struktur. Selanjutnya dilakukan desain sambungan menurut SNI 7971:2013 tentang baja canai dingin. Tujuan dari penelitian ini adalah menganalisis sambungan sekrup dengan SNI 7971:2013 dalam rangka atap baja ringan untuk mengetahui menganalisis sambungan apakah menjadi penyebab terjadinya instabilitas elemen rangka batang.

\section{B. TINJAUAN PUSTAKA}

\section{Desain Sambungan}

Untuk mencegah kegagalan sambungan dalam kondisi getas, kapasitas desain tarik sekrup harus 1,25 kali kasapitas desain untuk pull-out dan pull-cover. Kapasitas tarik maksimum untuk sekrup self-drilling seperti diterangkan dalam AS-3556 diberikan dalam tabel 1. Nilai yang diberikan di tabel 1 adalah untuk sekrup saja bukan untuk sambungan. Ketebalan pelat penyambung baja akan menentukan kekuatan sambungan. 
Tabel 1. Kuat Tarik Aksial Menentukan Untuk Sekrup Self-drilling

\begin{tabular}{cccc}
\hline \multirow{2}{*}{ Ukuran } & \multicolumn{3}{c}{ Kuat Tarik aksial maksimum $(\mathbf{k N})$} \\
\cline { 2 - 4 } & Type ASD & Type BSD & Type CSD \\
\hline No.6 & 4,35 & 4,35 & 5,33 \\
No.8 & 6,35 & 6,35 & 8,46 \\
No.10 & 7,5 & 8,6 & 10,01 \\
No.12 & 11,34 & 11,63 & 14,44 \\
No 14 & 14,95 & 16,15 & 18,9 \\
\hline
\end{tabular}

Menurut Peraturan Baja Ringan Indonesia SNI 7971:2013, kekuatan sambungan $(\mathrm{Vb})$ untuk kondisi rotasi sekrup (tilting) dihitung sebagai nilai terkecil dari rumus-rumus berikut ini:

$$
\begin{aligned}
\mathrm{V}_{\mathrm{b}} & =4,2 \sqrt{\left(\mathrm{t}_{2}^{3} \cdot \mathrm{d}_{\mathrm{f}}\right.} \cdot \mathrm{f}_{\mathrm{u} 1} \\
\mathrm{~V}_{\mathrm{b}} & =\mathrm{C} \cdot \mathrm{t}_{1} \cdot \mathrm{d}_{\mathrm{f}} \cdot \mathrm{f}_{\mathrm{u} 1} \\
\mathrm{~V}_{\mathrm{b}} & =\text { C.t }{ }_{2} \cdot \mathrm{d}_{\mathrm{f}} \cdot \mathrm{f}_{\mathrm{u} 2}
\end{aligned}
$$

Dengan :

$$
\begin{aligned}
\mathrm{V}_{\mathrm{b}}= & \begin{array}{l}
\text { Kapasitas tumpu nominal } \\
\text { bagian tersambung }
\end{array} \\
\mathrm{t}_{1}= & \text { Tebal lembaran yang } \\
& \text { kontak dengan kepala } \\
& \text { sekrup } \\
\mathrm{t}_{2}= & \text { Tebal lembaran yang tidak } \\
& \text { kontak dengan kepala } \\
& \text { sekrup } \\
\mathrm{d}_{\mathrm{f}}= & \text { Diameter sekrup nominal } \\
\mathrm{f}_{\mathrm{u} 1}= & \text { Tegangan ultimate } \\
& \text { lembaran yang kontak } \\
& \text { dengan kepala sekrup } \\
\mathrm{f}_{\mathrm{u} 2}= & \text { Tegangan ultimate } \\
& \text { lembaran yang tidak kontak } \\
& \text { dengan kepala sekrup }
\end{aligned}
$$

$$
\begin{aligned}
\mathrm{C}= & \text { Faktor tumpu sebagai } \\
& \text { fungsi perbandingan } \\
& \text { diameter sekrup nominal } \\
& \text { dan tebal lembaran }
\end{aligned}
$$

Diameter nominal sekrup adalah $\mathrm{d}_{\mathrm{f}}=5$ $\mathrm{mm}$. Nilai $\mathrm{C}$ ditentukan dengan rumus :

$$
\begin{gathered}
\mathrm{C}=3,3-0,1 \cdot \frac{\mathrm{d}_{\mathrm{f}}}{\mathrm{t}} \quad \text { Untuk } \\
6 \leq \frac{\mathrm{d}_{\mathrm{f}}}{\mathrm{t}} \leq 3
\end{gathered}
$$

\section{DATA DAN ANALISA DATA}

Penelitian dilakukan dengan melakukan pemodelan rangka atap baja canai dingin menggunakan SAP 2000 untuk mengetahui gaya dalam struktur. Selanjutnya dilakukan desain sambungan menurut SNI 7971:2013 tentang baja canai. Sambungan yang akan dianalisis merupakan sambungan rangka baja ringan dengan menggunakan self-drilling screw yang didesain menurut ketentuan SNI 7971:2013.

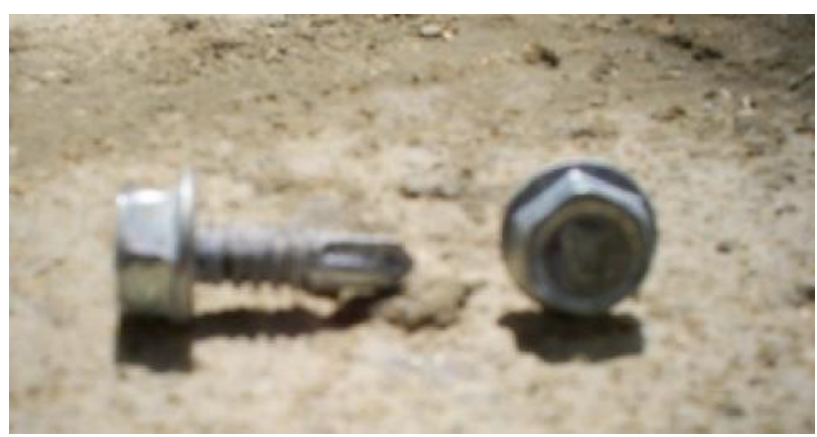

Gambar 1. Sekrup yang Digunakan Untuk Sambungan di Proyek 
Berdasarkan gambar 1, beberapa asumsi yang diambil dalam menganalisis kapasitas sambungan dari struktur rangka baja ringan antara lain:

a. Sambungan memenuhi persyaratan geometri dalam hal konfigurasi sekrup tiap sambungan

b. Sambungan diasumsikan cukup kuat menahan gaya-gaya dalam rangka baja ringan yang menahan kombinasi beban gravitasi, beban angin dan beban hujan.

Ada empat tipe sambungan yang akan dianalisis yaitu:

a. Bagian heel (elemen 1 dan 18) b. Bagian ridge (elemen 25-26 dan web 51 - web 52)

c. Joint antara - batang tekan (23-69), top chord (43-44), dan batang horizontal (D1)

d. Joint antara - batang dalam (67) dan bottom chord $(16,17,66)$

Perencanaan sambungan yang akan dilakukan meliputi perencanaan geometri dan kekuatannya terhadap tahanan tarik dan geser. Pada 4 joint struktur kuda-kuda rangka atap baja ringan yang diperkirakan membutuhkan karakteristik tahanan terbesar dalam bentuk sambungan yang sama.

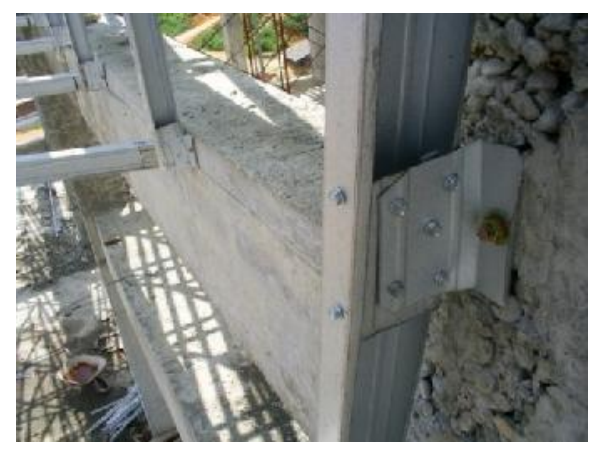

Gambar 2. Contoh Sambungan Pada Bagian Ujung

Pada struktur kuda-kuda rangka atap baja ringan, direncanakan sambungan pada 4 (empat) joint, yaitu joint 1 , joint 2 , joint 3 dan joint 4 . Adapun lokasi joint-joint tersebut dapat dilihat pada gambar 3 .
Gambar 3 menjelaskan lokasi joint-joint yang akan dianalisis. Jointjoint tersebut dipilih untuk mewakili lokasi-lokasi lain yang sejenis.

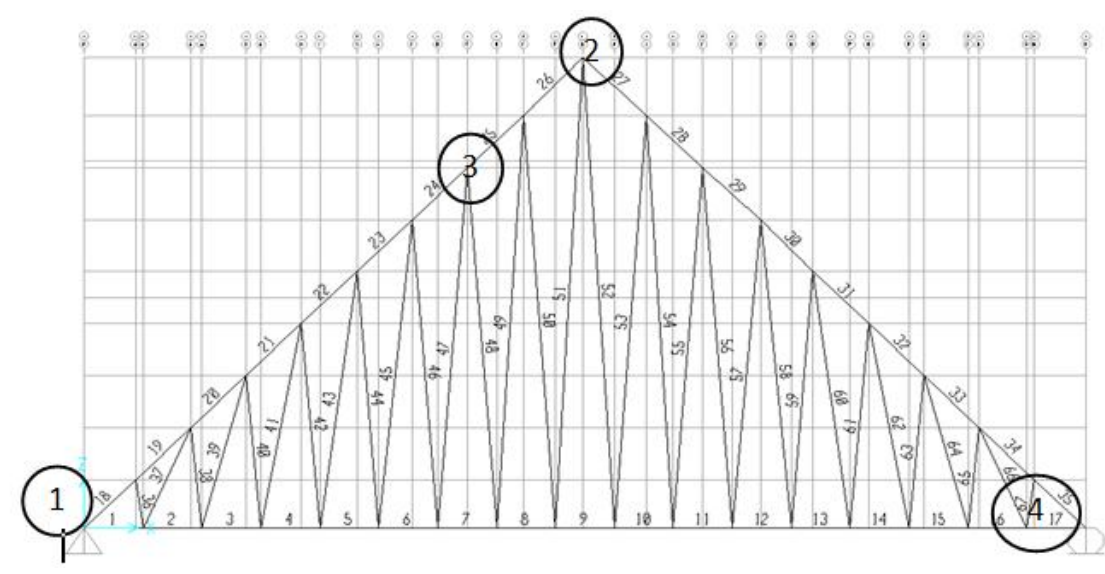

Gambar 3. Lokasi Joint Sambungan Baja Ringan yang akan Dianalisis 
D. HASIL DAN PEMBAHASAN

\section{Sambungan Pada Joint 1}

Pada joint 1 terdapat hubungan sambungan antara batang tekan 18 dengan batang tarik 1. Desain kapasitas sambungan sekrup untuk tipe Screw 1214 x 20 TASO dengan profil batang $\mathrm{C}$ 100.75 .75 dengan tebal $75 \mathrm{~mm}$ yang memiliki lubang lurus.

\section{Sambungan pada Joint 2}

Pada joint 2, terdapat hubungan sambungan antara batang tekan 25, batang tekan 26 , batang web 51 , dan batang web 52. Bentuk hubungan sambungan tersebut diilustrasikan dalam gambar 4 .

Untuk mengkondisikan agar titik kumpul gaya aksial bertemu pada satu titik, gusset plate dipakai pada joint 2 . Sambungan di atas berbentuk simetris sehingga analisis akan dilakukan pada salah satu sisi sambungan. Sambungan yang akan dianalisis adalah sambungan antara batang tekan 25 dengan web 51 atau sambungan batang tekan 26 dengan web 52. Gaya dalam maksimum yang terjadi antara kedua sisi sambungan tidak jauh berbeda. Pada batang tekan 25 dan 26 diperoleh gaya tekan sebesar $1.69703 \mathrm{kN}$ dan 1.85469 $\mathrm{kN}$. Sedangkan pada web 51 dan 52 diperoleh gaya dalam maksimum sebesar $0.199 \mathrm{kN}$ dan $0.185 \mathrm{kN}$. Nilai gaya dalam yang dipakai dalam analisis kapasitas sambungan adalah gaya dalam yang lebih besar. Sisi sambungan yang akan didesain adalah joint pada batang tekan 25 dengan web 51 .

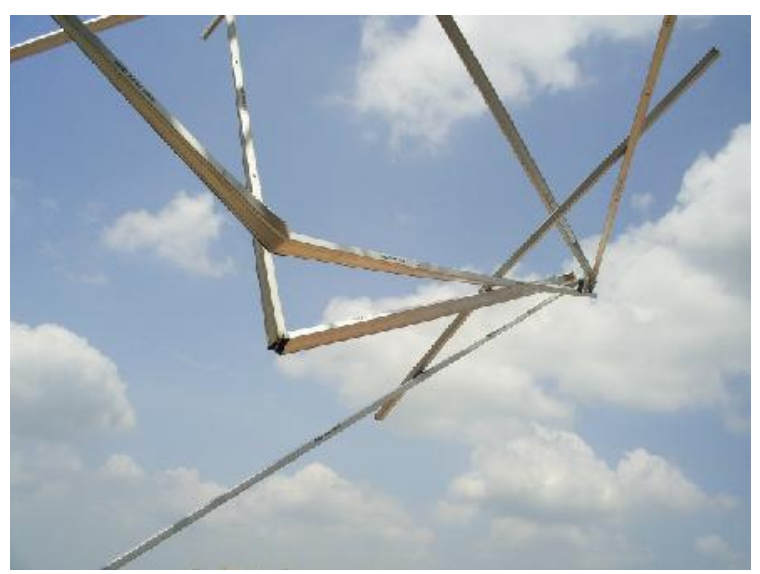

Gambar 4. Pengamatan Keruntuhan pada Joint 2

\section{Sambungan Pada Joint 3}

Pada joint 3, terdapat hubungan sambungan antara batang tekan 23, batang tekan 69, batang web 43 dan batang web 44 .

\section{Sambungan pada Joint 4}

Pada joint 4, terdapat hubungan sambungan antara batang tarik 16, batang tarik 17, batang web 66, dan batang web 67 .

\section{Perhitungan Analisis Kapasitas Screw}

Profil batang adalah C 100.75.75 dengan tebal $75 \mathrm{~mm}$ yang memiliki lubang lurus dengan tipe sekrup berupa Screw $12-14$ x 20 TASO.

Spesifikasi yaitu :

Diameter sekrup, $d_{f}=5,3 \mathrm{~mm}$

Diameter kepala ring dari sekrup adalah $\mathrm{D}_{\mathrm{k}}=14,2 \mathrm{~mm}$

$\mathrm{t}_{2}=1 \mathrm{~mm}, \mathrm{t}_{1}=1 \mathrm{~mm}$ 
Kapasitas tegangan leleh $\left(\mathrm{f}_{\mathrm{y}}\right)$

$=550 \mathrm{MPa}$

Kapasitas tegangan tarik $\left(\mathrm{f}_{\mathrm{u}}\right)$

$=1,17 . \mathrm{f}_{\mathrm{y}}=643,5 \mathrm{MPa}$

a. Kapasitas Geser Batang Tarik 1

Pelubangan dengan sekrup $t_{2} / t_{1}$

$=1,0 \leq 1,0$

Kapasitas tumpu dari nominal bagian yang tersambung diambil terkecil dari :

$$
\begin{aligned}
\mathrm{V}_{\mathrm{b}} & =4,2 \sqrt{\left(\mathrm{t}_{2}^{3} \cdot \mathrm{d}_{\mathrm{f}}\right.} \cdot \mathrm{f}_{\mathrm{u} 1} \\
& =4,2 \sqrt{\left(2_{2}^{3} \cdot(5,3)\right.} \cdot(643,5) \\
& =1,746 \times 10^{4} \mathrm{~N} \\
\mathrm{~V}_{\mathrm{b}} & =\mathrm{C} \cdot \mathrm{t}_{2} \cdot \mathrm{d}_{\mathrm{f}} \cdot \mathrm{f}_{\mathrm{u} 2} \\
& =(2,7) \cdot(2) \cdot(5,3) \cdot(643,5) \\
& =1,842 \times 10^{4} \mathrm{~N}
\end{aligned}
$$

Yang menentukan adalah kondisi tilting, maka $\mathrm{V}_{\mathrm{b}}=17600 \mathrm{~N}$

$$
\begin{aligned}
\phi \mathrm{V}_{\mathrm{b}} & =0,5 \times\left(1,746 \times 10^{4}\right) \\
& =8,799 \times 10^{3} \mathrm{~N}
\end{aligned}
$$

Kapasitas geser desain sekrup disyaratkan sebesar $1,25 . \phi \mathrm{V}_{\mathrm{b}}$

$$
\begin{aligned}
\mathrm{V}_{\mathrm{n}} & =1,25 \times\left(8,779 \times 10^{3}\right) \\
& =1,1 \times 10^{3} \mathrm{~N}
\end{aligned}
$$

Jumlah sekrup yang dibutuhkan :

$$
\begin{aligned}
\mathrm{P}_{\mathrm{u}} & =34038 \mathrm{~N} \\
\mathrm{n}_{\mathrm{s}} & =\frac{\mathrm{P}_{\mathrm{u}}}{\mathrm{V}_{\mathrm{bn}}} \\
& =3,868 \\
\mathrm{n}_{\mathrm{s}} & =4
\end{aligned}
$$

Cek kapasitas geser sekrup :

$$
\begin{array}{lll}
\mathrm{n}_{\mathrm{s}} \cdot \mathrm{V}_{\mathrm{n}} & \geq \mathrm{P}_{\mathrm{u}} \\
4 \times\left(1,1 \times 10^{3}\right) & \geq 34038 \\
42550 \mathrm{~N} & \geq 34038 \mathrm{~N} \quad \mathrm{OK}
\end{array}
$$

b. Kapasitas Geser Batang Tekan 18

$$
\begin{aligned}
& \mathrm{P}_{\mathrm{u}}=6567 \mathrm{~N} \\
& \mathrm{~V}_{\mathrm{bu}} \leq \phi \mathrm{b}_{\mathrm{u}} \cdot \mathrm{V}_{\mathrm{b}}
\end{aligned}
$$

Perbandingan pelat badan dengan tebal badan $\mathrm{t}_{2}=1 \mathrm{~mm}, \mathrm{t}_{1}=1 \mathrm{~mm}$

$$
\begin{aligned}
& \frac{\mathrm{t}_{2}}{\mathrm{t}_{1}}=1 \\
& \frac{\mathrm{t}_{2}}{\mathrm{t}_{1}}=1 \leq 1,0
\end{aligned}
$$

Kapasitas tumpu dari nominal bagian yang tersambung diambil dari yang terkecil dari :

$$
\begin{aligned}
\mathrm{V}_{\mathrm{b} 1} & =4,2 \sqrt{\left(\mathrm{t}_{2}^{3} \cdot \mathrm{d}_{\mathrm{f}}\right.} \cdot \mathrm{f}_{\mathrm{u} 2} \\
& =6,222 \times 10^{3} \mathrm{~N} \\
\mathrm{C} & =2,7 \\
\mathrm{f}_{\mathrm{u} 1} & =643,5 \mathrm{MPa} \\
\mathrm{V}_{\mathrm{b} 2} & =\text { C. } \mathrm{t}_{1} \cdot \mathrm{d}_{\mathrm{f}} \cdot \mathrm{f}_{\mathrm{u} 1} \\
& =9,208 \times 10^{3} \mathrm{~N}
\end{aligned}
$$

Yang menentukan adalah kondisi tilting, maka $\mathrm{V}_{\mathrm{b}}=6,222 \times 10^{3} \mathrm{~N}$

$$
\begin{aligned}
\phi \mathrm{V}_{\mathrm{b}} & =0,5 \times\left(6,222 \times 10^{3}\right) \\
& =3,111 \times 10^{3} \mathrm{~N}
\end{aligned}
$$

Kapasitas geser desain sekrup disyaratkan sebesar $1,25 . \phi \mathrm{V}_{\mathrm{b}}$

$$
\begin{aligned}
\mathrm{V}_{\mathrm{n}} & =1,25 \times\left(3,111 \times 10^{3}\right) \\
& =3,889 \times 10^{3} \mathrm{~N}
\end{aligned}
$$


Jumlah sekrup yang dibutuhkan :

$$
\begin{aligned}
\mathrm{P}_{\mathrm{u}} & =6557 \mathrm{~N} \\
\mathrm{n}_{\mathrm{s}} & =\frac{\mathrm{P}_{\mathrm{u}}}{\mathrm{V}_{\mathrm{bn}}} \\
& =2,108 \\
\mathrm{n}_{\mathrm{s}} & =3
\end{aligned}
$$

Cek kapasitas geser sekrup :

$$
\begin{array}{llll}
\mathrm{n}_{\mathrm{s}} \cdot \mathrm{V}_{\mathrm{n}} & \geq \mathrm{P}_{\mathrm{u}} & \\
3 \times\left(3,889 \times 10^{3}\right) & \geq 6557 & \\
8196 \mathrm{~N} & \geq 6557 \mathrm{~N} & \text { OK }
\end{array}
$$

Jadi jumlah sekrup yang diperlukan pada joint 1 sebanyak 4 buah sekrup nomor 12 tipe screw 12-14 x 20 taso.

c. Kapasitas Tarik Sekrup Batang Tekan $18=$ batang tarik no 1

$$
\begin{aligned}
\text { Pull Out } & \\
\mathrm{N}_{\text {ou }} & =0,85 \times 2 \times 5,3 \times 550 \\
& =2478 \mathrm{~N}
\end{aligned}
$$$$
\text { Pull Over }
$$

$$
\begin{aligned}
\mathrm{N}_{\text {ou }} & =1,5 \times 2 \times 12,7 \times 550 \\
& =11710 \mathrm{~N}
\end{aligned}
$$

Pull Out lebih menentukan sehingga $\mathrm{Nt}=2478 \mathrm{~N}$

$$
\begin{aligned}
\phi=0,5 \rightarrow \phi N t & =0,5 * 2478 \mathrm{~N} \\
& =1239 \mathrm{~N}
\end{aligned}
$$

Kuat tarik desain sekrup disyaratkan sebesar $1,25 \times 1239=1549 \mathrm{~N}$

d. Kapasitas Tarik Elemen Pada Bagian Sambungan Batang Tarik 1

$$
\mathrm{N}_{\mathrm{u}}=34038 \mathrm{~N}
$$

$$
\begin{array}{rl}
\mathrm{s}_{\mathrm{f}} & =25 \mathrm{~mm} \\
\mathrm{~A}_{\mathrm{n}} & =264 \mathrm{~mm}^{2} \\
\mathrm{~L} & =1278 \mathrm{~mm} \\
\mathrm{r}_{\mathrm{f}} & =\frac{\frac{\mathrm{N}_{\mathrm{u}}}{\mathrm{n}_{\mathrm{s}}}}{94416,3 \mathrm{~N}} \\
& =0,171 \\
& =\left(1-\mathrm{r}_{\mathrm{f}}+\frac{2,5 \cdot \mathrm{r}_{\mathrm{f}} \cdot \mathrm{d}_{\mathrm{f}}}{\mathrm{s}_{\mathrm{f}}}\right) \cdot \mathrm{f}_{\mathrm{u}} \cdot \mathrm{A}_{\mathrm{g}} \\
\mathrm{N}_{\mathrm{f}} & 6,169 \times 10^{4} \mathrm{~N} \\
\mathrm{~N}_{\mathrm{f}} & \geq \mathrm{f}_{\mathrm{u}} \cdot \mathrm{A}_{\mathrm{g}} \\
6,169 \times 10^{4} \mathrm{~N} \quad \geq 6708 \mathrm{~N} \quad \mathrm{OK}
\end{array}
$$

Kapasitas sambungan pada joint 1 ditentukan oleh kapasitas geser sekrup. Desain kapasitas geser pada joint ini sebesar $11340 \mathrm{~N}$ sedangkan gaya dalam maksimum bekerja sebesar 7378.59375 N. Hal ini berarti kapasitas geser sedikit di atas gaya dalam maksimum yang bekerja. Sedangkan, kapasitas tarik profil sebesar $1549 \mathrm{~N}$ jauh kapasitas geser yang bekerja. Perhitungan screw selanjutnya dilakukan dalam tabel 2 .

Kapasitas sambungan pada kasus ini ditentukan oleh kapasitas geser sekrup. Desain kapasitas geser sedikit di atas gaya dalam maksimum yang bekerja. Sedangkan, kapasitas tarik profil jauh kapasitas geser yang bekerja. 
Tabel 2. Analisis Sambungan

\begin{tabular}{|c|c|c|c|c|c|c|c|c|c|c|c|c|}
\hline Joint & $\underset{\text { Batang }}{\text { Jenis }}$ & t1 & $\mathbf{t} 2$ & t2/t 1 & $\begin{array}{l}\mathrm{Nu} \\
(\mathrm{N})\end{array}$ & $\begin{array}{c}\text { Vb } \\
\text { titling }\end{array}$ & Vb 1 & Vb 2 & $\mathbf{V}$ desain & $\begin{array}{c}1,25 \mathrm{fV} \\
(\mathrm{N})\end{array}$ & $\mathbf{N u} / \mathbf{V b}$ & $\mathbf{n}$ \\
\hline \multicolumn{13}{|l|}{ Joint 1} \\
\hline 1 & tarik & 2 & 2.3 & 1.5 & 35631 & 20999.53 & 11805.75 & 17708.625 & 11805.75 & 7378.59 & 4.829 & 5 \\
\hline 18 & tekan & 2 & 2.3 & 1.5 & 6567 & 20999.53 & 11805.75 & 17708.625 & 11805.75 & 7378.59 & 0.890 & 1 \\
\hline \multicolumn{13}{|l|}{ Joint 2} \\
\hline 25 & tekan & 2 & 2.3 & 1.5 & 929 & 20999.53 & 11805.75 & 17708.625 & 11805.75 & 7378.59 & 0.126 & 1 \\
\hline 26 & tekan & 2 & 2.3 & 1.5 & 918 & 20999.53 & 11805.75 & 17708.625 & 11805.75 & 7378.59 & 0.124 & 1 \\
\hline 51 & tarik & 2 & 2.3 & 1.5 & 15477 & 20999.53 & 11805.75 & 17708.625 & 11805.75 & 7378.59 & 2.098 & 3 \\
\hline 52 & tarik & 2 & 2.3 & 1.5 & 15836 & 20999.53 & 11805.75 & 17708.625 & 11805.75 & 7378.59 & 2.146 & 3 \\
\hline \multicolumn{13}{|l|}{ Joint 3} \\
\hline 23 & tekan & 2 & 2.3 & 1.5 & 2673 & 20999.53 & 11805.75 & 17708.625 & 11805.75 & 7378.59 & 0.362 & 1 \\
\hline 43 & tarik & 2 & 2.3 & 1.5 & 9572 & 20999.53 & 11805.75 & 17708.625 & 11805.75 & 7378.59 & 1.297 & 2 \\
\hline 44 & tarik & 2 & 2.3 & 1.5 & 10703 & 20999.53 & 11805.75 & 17708.625 & 11805.75 & 7378.59 & 1.451 & 2 \\
\hline 69 & tekan & 2 & 2.3 & 1.5 & 1852 & 20999.53 & 11805.75 & 17708.625 & 11805.75 & 7378.59 & 0.251 & 1 \\
\hline \multicolumn{13}{|l|}{ Joint 4} \\
\hline 16 & tarik & 2 & 2.3 & 1.5 & 7745 & 20999.53 & 11805.75 & 17708.625 & 11805.75 & 7378.59 & 1.050 & 2 \\
\hline 17 & tarik & 2 & 2.3 & 1.5 & 6103 & 20999.53 & 11805.75 & 17708.625 & 11805.75 & 7378.59 & 0.827 & 1 \\
\hline 66 & tarik & 2 & 2.3 & 1.5 & 5758 & 20999.53 & 11805.75 & 17708.625 & 11805.75 & 7378.59 & 0.780 & 1 \\
\hline 67 & tekan & 2 & 2.3 & 1.5 & 324 & 20999.53 & 11805.75 & 17708.625 & 11805.75 & 7378.59 & 0.044 & 1 \\
\hline
\end{tabular}

\section{E. KESIMPULAN}

Sambungan cukup kuat menahan gaya-gaya dalam rangka baja ringan yang menahan kombinasi beban gravitasi dan beban angin,beban hujan, sehingga sambungan bukanlah menjadi penyebab terjadinya keruntuhan struktur rangka atap. Kegagalan sambungan dipengaruhi oleh mode bearing. Oleh karena kapasitas geser desain yang diperoleh lebih besar dari kapasitas tariknya, jumlah sekrup yang digunakan lebih sedikit. Kapasitas sambungan pada kasus ini ditentukan oleh kapasitas geser sekrup. Desain kapasitas geser sedikit di atas gaya dalam maksimum yang bekerja. Sedangkan, kapasitas tarik profil jauh kapasitas geser yang bekerja.

\section{DAFTAR PUSTAKA}

Amalia R., 2012, Studi Eksperimental dan Analisis Rangka Atap Tipe Howe menggunakan Profil Baja Ringan, Tugas Akhir, Program S1 Teknik Sipil Universitas Sriwijaya, Sumatera Selatan.

Ariyavinanta E., 2015, Pengembangan

Spreadsheet Untuk Perhitungan Kapasitas Baja Canai Dingin dengan Pengaku Berdasarkan SNI 7971:2013, Tugas Akhir, Program S1 Program Studi Teknik Sipil Universitas Kristen Petra, Surabaya. 
Anggara P.D., 2014, Pengaruh Jarak Screw Terhadap Kekuatan Sambungan Pada Baja Ringan, Jurnal Rekayasa Teknik Sipil, Volume 3 Nomor 1 : 149-157.

Badan Standarisasi Nasional, 2013, Tata Cara Perencanaan Struktur Baja Canai Dingin SNI 03-79712013, Bandung.

Firmansyah L.V., 2014, Pengaruh Berbagai Jenis Screw Terhadap Kuat Tarik dan Kuat Geser Sambungan Baja Ringan, Jurnal Rekayasa Teknik Sipil, Volume 3 Nomor $1:$ 44-53.

Rhodes J., 2013, Formed Steel Structure, Cambridge University Press, Cambridge.

Kurniawan 2008, Analisis Baja Ringan dengan Baja Konvensional, Tugas Akhir, Program S1 Teknik Sipil Universitas Diponegoro, Bandung.

Nur K., 2012, Analisis Stabilitas Elemen Baja Ringan Sebagai Bahan Alternatif Pengganti Baja Konvensional Pada Rangka Batang (Studi Kasus Rangka Atap Gedung Fakultas Teknik UNG), Laporan Penelitian BNBP
Teknik Sipil, Universitas Negeri Gorontalo.

Nurjaman S., dkk., 2008, Analisis Sambungan Rangka Atap Baja Ringan Yang Didesain Menurut As 4600 Terhadap Beban Gempa Di Indonesia, Tugas Akhir, Program S1 Teknik Sipil Institut Teknologi Bandung, Bandung.

Rahmat S.B., 2010, Stabilitas KudaKuda Baja Ringan Star Truss Type C (Studi Kasus : Pengujian Kuda-kuda Baja Ringan Bentang 6 m), Tugas Akhir, Program S1 Teknik Sipil Fakultas Teknik Universitas Gadjah Mada, Yogyakarta.

Sulaeman, dkk., 2013, Artikel: Analisa Beban Ultimit Struktur Rangka Atap Sentris Dan Non Sentris Menggunakan Profil Baja Ringan, Jurusan Teknik Sipil Universitas Sriwijaya, Palembang. Standards Australia Limited/Standards New Zealand, 2005, Cold Form Steel Structures AS/NZS 4600:2005.

Yu W.W., 2000, Cold Formed Steel Design, Third Edition, John Wiley \&Sons, INC., New York. 